\title{
Fuzzy logic filtering of radar reflectivity to remove non-meteorological echoes using dual polarization radar moments
}

\author{
D. R. L. Dufton ${ }^{1,2}$ and C. G. Collier ${ }^{1,2}$ \\ ${ }^{1}$ Institute for Climate and Atmospheric Science, University of Leeds, Leeds, UK \\ ${ }^{2}$ National Centre for Atmospheric Science, University of Leeds, Leeds, UK \\ Correspondence to: D. R. L. Dufton (eedrld@leeds.ac.uk) \\ Received: 15 April 2015 - Published in Atmos. Meas. Tech. Discuss.: 18 May 2015 \\ Revised: 12 August 2015 - Accepted: 16 September 2015 - Published: 1 October 2015
}

\begin{abstract}
The ability of a fuzzy logic classifier to dynamically identify non-meteorological radar echoes is demonstrated using data from the National Centre for Atmospheric Science dual polarisation, Doppler, X-band mobile radar. Dynamic filtering of radar echoes is required due to the variable presence of spurious targets, which can include insects, ground clutter and background noise. The fuzzy logic classifier described here uses novel multi-vertex membership functions which allow a range of distributions to be incorporated into the final decision. These membership functions are derived using empirical observations, from a subset of the available radar data. The classifier incorporates a threshold of certainty ( $25 \%$ of the total possible membership score) into the final fractional defuzzification to improve the reliability of the results. It is shown that the addition of linear texture fields, specifically the texture of the cross-correlation coefficient, differential phase shift and differential reflectivity, to the classifier along with standard dual polarisation radar moments enhances the ability of the fuzzy classifier to identify multiple features. Examples from the Convective Precipitation Experiment (COPE) show the ability of the filter to identify insects (18 August 2013) and ground clutter in the presence of precipitation (17 August 2013). Medium-duration rainfall accumulations across the whole of the COPE campaign show the benefit of applying the filter prior to making quantitative precipitation estimates. A second deployment at a second field site (Burn Airfield, 6 October 2014) shows the applicability of the method to multiple locations, with small echo features, including power lines and cooling towers, being successfully identified by the classifier without modification of the membership functions from the previous deploy-
\end{abstract}

ment. The fuzzy logic filter described can also be run in near real time, with a delay of less than $1 \mathrm{~min}$, allowing its use on future field campaigns.

\section{Introduction}

Weather radars (henceforth just radar) are a major component of many national weather services' capabilities, and the introduction of dual polarisation across these networks presents the opportunity to further improve the quality of the data available from these radar. With the ever increasing availability of high-resolution weather forecasting models and multi-dimensional flood models, high-resolution quantitative precipitation estimates (QPE) are in great demand for the assimilation of boundary conditions, output validation and hydrological hindcasting. Given the high spatial and temporal resolution of these models, the current status quo of interpolated rain gauge data (Shao et al., 2012; Rauthe et al., 2013; Mariani et al., 2014) or gauge-adjusted radar data (Collier, 1986; Löwe et al. , 2014, for example) present a high degree of uncertainty, which should be lessened by establishing the use of dual polarisation radar QPE (Villarini and Krajewski, 2010). One of the benefits of dual polarisation QPE lies in correcting the many sources of uncertainty present in weather radar measurements, particularly attenuation, uncertain rainfall-reflectivity relationships, beam blockage and spurious echoes.

One of the most prevalent sources of uncertainty in radar data is the contamination of returns by spurious echoes, par- 
ticularly ground clutter (echoes produced when the beam intersects the ground, including buildings and vegetation). This is often intensified by anomalous beam propagation (AP) where the radar beam is refracted towards the ground by strong gradients in the refractive index of the atmosphere. Other sources of non-meteorological echoes include biological scatterers (typically insects and birds), sea-clutter and chaff. Removing these spurious echoes is possible using either static techniques for known clutter, signal-level correction of the return pulse (Torres and Zrnić, 1999; Nguyen et al., 2008) or dynamic filtering of the single polarisation (Steiner and Smith, 2002) or dual polarisation moment data (Chandrasekar et al., 2013). Static maps, usually developed over time with summary statistics, are reasonably successful at removing the effect of ground clutter (Harrison et al., 2014, 2000), yet are insufficient when AP increases the area of the returns and cannot remove echoes from other, nonmeteorological sources. Dynamic systems that respond to the variation in ground clutter returns have been developed as a response to these issues. Signal level, spectral filtering of the raw IQ data received by the radar is one approach to this problem (Doviak and Zrnić, 1984). As ground clutter has a near-zero Doppler velocity and a narrow spectral width the returns from clutter can be removed, however this can lead to the removal of weather echoes which also have zero radial velocity, along the so-called zero-velocity isodop (Hubbert et al., 2009). Both of these schemes also fail to account for other sources of spurious echoes. Dynamic filtering using dual polarisation moments presents itself as a capable solution, as it can account for the zero-velocity isodop and identify other non-meteorological targets, such as insects. One noticeable feature of these spurious returns is the ease at which they can be identified by eye, particularly on a clear day, while they also have distinct polarimetric signatures which aid their identification.

\subsection{Polarimetric signatures of typical radar echoes}

Dual polarisation radars, transmitting horizontally and vertically aligned signals, allow more detailed observations of the atmosphere than those transmitting along a single plane. Here we present a review of the polarimetric signatures from typical radar echoes, focusing on those variables available for this study, which will contribute to the identification of radar echoes. For a more detailed description of how dual polarimetry functions see Bringi and Chandrasekar (2001) for example.

\subsubsection{Differential reflectivity $\left(Z_{D R}\right)$}

Differential reflectivity (the observed difference between the horizontally and vertically polarized reflectivity measurements), was first proposed as a method of observing rainfall by Seliga and Bringi (1976), with the aim being to quantify the rainfall drop size distribution. Due to the oblate spheroidal shape of falling raindrops, they produce a low positive reflectivity shift in the horizontal, relative to the vertical, which is proportional to their size. Scattering simulations and field measurements show that $Z_{\mathrm{DR}}$ ranges from $0.2 \mathrm{~dB}$ in very light drizzle to over $4.5 \mathrm{~dB}$ for very large rain drops (greater than $4 \mathrm{~mm}$ diameter) (Seliga and Bringi, 1978; Hall et al., 1984; Balakrishnan and Zrnić, 1990, for example). As drop size diameter increases non-Rayleigh scattering can occur, this effect happens sooner at shorter radar wavelengths. This effect is most prevalent at C-band, with strong resonance above $4.5 \mathrm{~mm}$ while $\mathrm{X}$-band experiences minor resonance at around 3-4 mm diameter (Ryzhkov and Zrnić, 2005).

Mueller and Larkin (1985) made the first dual polarisation observations of insects, using the S-band CHILL radar. Earlier, single polarisation, observations had successfully attributed some clear air radar echoes to both insect and bird targets (Plank, 1956; Harper, 1958, for example). The dual polarisation observations show $Z_{\mathrm{DR}}$ to be a function of insect orientation, ranging from $0.5 \mathrm{~dB}$ if the insects are aligned radially (head-on/tail-on) to the radar, increasing to $5 \mathrm{~dB}$ when viewed azimuthally (broadside) to the radar. More recent studies have confirmed these results with a range of radar systems, with the typical reported insect $Z_{\mathrm{DR}}$ range being 29 dB (Zrnić and Ryzhkov, 1998; Chilson et al., 2012).

In contrast, ground clutter returns have no obvious $Z_{\mathrm{DR}}$ signature, being broadly distributed, with an average value of $0 \mathrm{~dB}$ (reported in Zrnić and Ryzhkov, 1999; Zrnić et al., 2006, for example).

\subsubsection{Copolar cross correlation coefficient $\left(\rho_{\mathrm{HV}}\right)$}

The copolar cross correlation coefficient (the correlation between the horizontal and vertical received powers within a pulse volume) is another parameter often used as a discriminator between precipitation and non-meteorological echoes (Zrnić and Ryzhkov, 1999; Chandrasekar et al., 2013). Meteorological echoes return a $\rho_{\mathrm{HV}}$ of greater than 0.8 , with pure phase echoes (rain/snow only) returning much greater $\rho_{\mathrm{HV}}$ values ( $>0.97$ for pure rain) (Balakrishnan and Zrnić, 1990). However, biological scatterers and ground targets return a much lower cross-correlation, typically less than 0.7 (Zrnić and Ryzhkov, 1998; Zrnić et al., 2006).

\subsubsection{Differential phase shift $\left(\Psi_{\mathrm{DP}}\right)$}

The total differential phase shift (the observed phase difference between the received horizontal and vertical pulses) contains two components, the backscatter differential phase $(\delta)$ and the propagation differential phase $\Phi_{\mathrm{DP}}$ (Bringi and Chandrasekar, 2001) and may also contain the transmitted system offset between the pulses. Large backscatter differential phase shifts are known to occur as a result of insects and birds (Zrnić and Ryzhkov, 1998), and also ground clutter (Zrnić et al., 2006). Meanwhile, propagation differential 
phase is near zero in light precipitation, scaling smoothly with volume concentration of meteorological scatterers, often being converted to specific differential phase (the range derivative) for hydro-meteorological applications. Therefore, where $\Phi_{\mathrm{DP}}$ is observed to be monotonically increasing with low noise, rainfall can be inferred, while variable signals with large fluctuations are indicative of non-meteorological scatterers.

\subsection{Artificial intelligence filtering of returns using radar signatures}

These distinctive polarimetric signatures have led to the development of several artificial intelligence type, dynamic filtering algorithms including the use of decision trees, neural networks, Bayesian classification and fuzzy logic classification (Berenguer et al., 2006; Lakshmanan et al., 2007; Chandrasekar et al., 2013).

Fuzzy logic classification schemes have been implemented for the filtering of spurious echoes (Gourley et al., 2007; Rico-Ramirez and Cluckie, 2008) and also for the identification of hydrometeors (Dolan and Rutledge, 2009; Park et al., 2009). These schemes all rely on the basic principles of fuzzy logic (Zadeh, 1983), but take different approaches to the variables, classifications and post processing used. Gourley et al. (2007), for example, limit the fuzzy classifier to three fields (texture of specific differential phase $\left(\sigma\left(\Phi_{\mathrm{DP}}\right)\right)$, texture of differential reflectivity $\left(\sigma\left(Z_{\mathrm{DR}}\right)\right)$ and cross-correlation coefficient $\left.\left(\rho_{\mathrm{HV}}\right)\right)$, using probability density functions to define their sets. They then apply post-fuzzy reclassification based on an additional three fields (velocity, reflectivity and $\left.\Phi_{\text {DP }}\right)$. Their scheme successfully identifies non-precipitating echoes in a range of cases. In contrast, Dolan and Rutledge (2009) use five fields, including temperature, to define their one-dimensional beta functions (MBFs) for hydrometeor classification. In this way, fuzzy logic presents a highly adaptable framework, the advantage of which is the ability to use the increasing number of moments available from dual polarisation weather radars to produce dynamic filters. These schemes are highly adaptable and can be trained with a limited volume of both empirical and simulated data, which allows rapid implementation in the field. When more data are available a more autonomous clustering algorithm, such as GDBSCAN (Sander et al. , 1998) or agglomerative hierarchical clustering (Grazioli et al., 2015) can be implemented to remove the need for subjective human identification of training data, which is one of the current limitations of fuzzy logic and similar trained machine learning techniques.

The fuzzy classification scheme presented here uses novel radial texture parameters of dual polarisation variables (including $\left.\rho_{\mathrm{HV}}\right)$, corrected for range effects, in combination with standard dual polarisation moments and beam height to identify and remove spurious echoes in two UK locations. The fuzzy filter has been developed using data from an Xband dual-polarimetric, Doppler, mobile radar (see follow-
Table 1. NCAS Meteor 50DX specifications.

\begin{tabular}{ll}
\hline Performance parameters & Specifications \\
\hline Half power beam width & $0.98^{\circ}$ \\
Peak transmit power & $83 \mathrm{~kW}$ \\
Antenna diameter & $2.4 \mathrm{~m}$ \\
Dual polarisation & Simultaneous $\mathrm{H} \& \mathrm{~V}$ \\
Radome & None \\
Range resolution & $0.150 \mathrm{~km}$ \\
Operational range & $150 \mathrm{~km}$ \\
Pulse repetition frequency & $1000 / 800 \mathrm{~Hz}$ \\
Pulse width & $1 \mu \mathrm{s}$ \\
Antenna speed & $20^{\circ} \mathrm{s}-1$ \\
Scan duration & $240 \mathrm{~s}$ \\
Volume elevations & $10\left(0.5,1.5, \ldots, 8.5,9.5^{\circ}\right)$ \\
\hline
\end{tabular}

ing section for details), with empirically derived membership functions of variable form. Currently the scheme has been used for reprocessing data for use in validating numerical weather models, and for assessing the sensitivity of simple hydrological models to rainfall input uncertainty. The scheme has also been designed to compute classifications in near real time, allowing filtering of echoes during future radar deployments. The following sections will describe the radar used in the project and its deployment, the fuzzy filtering methodology used in this work, including the derivation of the empirical membership functions used and the combination of these functions using fuzzy logic and finally present examples of the fuzzy filter applied to varied test cases.

\section{Mobile X-band radar and its deployment}

$\mathrm{X}$-band radars are becoming increasingly popular as an alternative or an addition to S- and C-band radar networks, particularly for urban hydrology and in complex terrain (Delrieu and Creutin, 1991; Michelson et al., 2005). The main advantage of X-band is the higher achievable resolution at a lower cost, particularly in areas where long range is unnecessary or impossible (typically beyond $50 \mathrm{~km}$ ). The mobile radar used in this study is a modified Meteor 50DX (Selex ES GmbH) dual-polarised Doppler radar, fitted with a larger, $2.4 \mathrm{~m}$, antenna to produce a narrower beam-width $\left(0.98^{\circ}\right)$. Full technical details for the radar are shown in Table 1, with scan specific parameters given for the main deployments referenced in this paper. The data used in this study were obtained during the Convective Precipitation Experiment (COPE) (Bennett, 2015), a 3 month field deployment at Davidstow Airfield, in the south-west UK (Blyth et al., 2015) and during single day testing deployments at Burn Airfield in North Yorkshire, UK. Both locations (shown in Fig. 1) have clear clutter targets, caused by topography, buildings, wind turbines and vegetation. This presented the opportunity to calibrate and validate the fuzzy filter based on observa- 


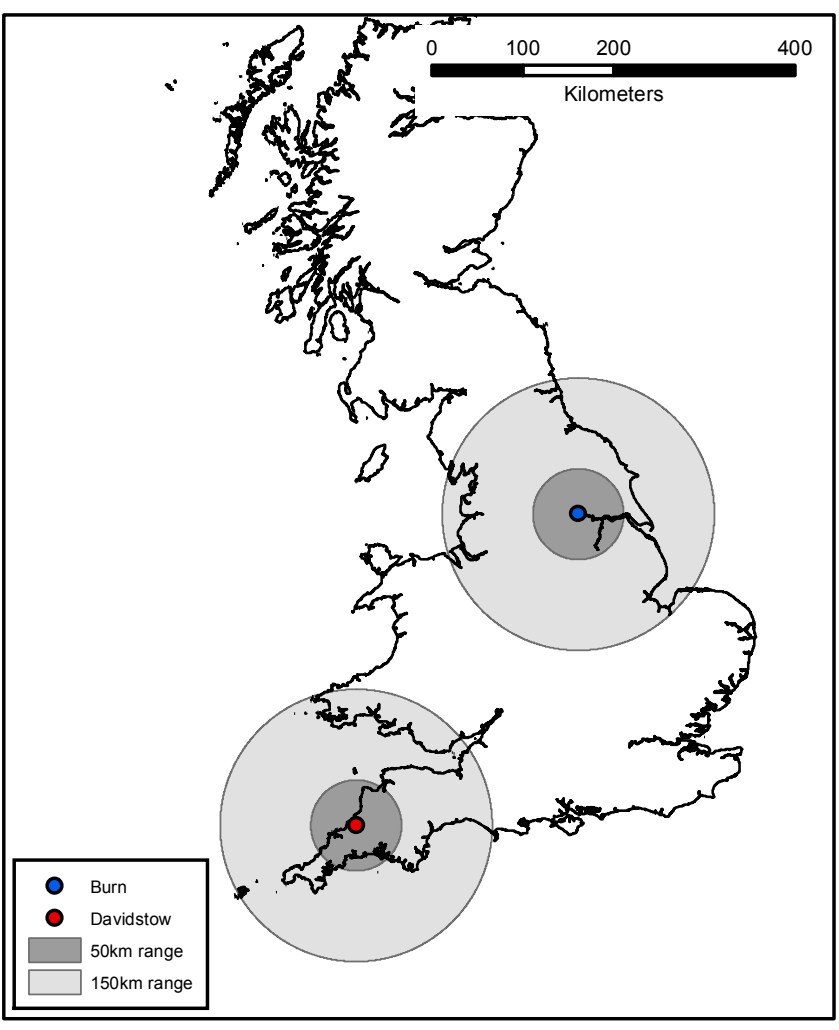

Figure 1. Location of the Davidstow and Burn field deployment sites used in this study.

tions resulting from known targets. The site at Davidstow observes clutter from the high topography of Bodmin Moor (within $10 \mathrm{~km}$ ) and Dartmoor (at approx. $40 \mathrm{~km}$ range), from Davidstow woods to the south-west $(2 \mathrm{~km})$, from the wind farm at St Clether (6 km east) and radio masts to the northwest. The site at Burn suffers from nearby vegetation (within $2 \mathrm{~km}$ ), along with three local power stations and their associated power lines. There is also high topography to the northwest. These features are all visible in Fig. 2, which shows example data from both deployment sites. Prior to the analysis presented here, reflectivity and differential reflectivity were corrected for radar miss-calibration and frequency drift using a modified version of the self consistency approach presented by Gourley et al. (2009). Correction for attenuation has not been applied, as correction using the commonly applied ZPHI method (Testud et al., 2000) requires clutter filtered data to accurately distribute attenuation along the rain path. Attenuation correction of the data will follow in future work, after the application of the clutter filter and removal of non-meteorological echoes.

\section{Filtering methodology}

Filtering requires the identification of spurious or unwanted information and its removal, while passing through the re-
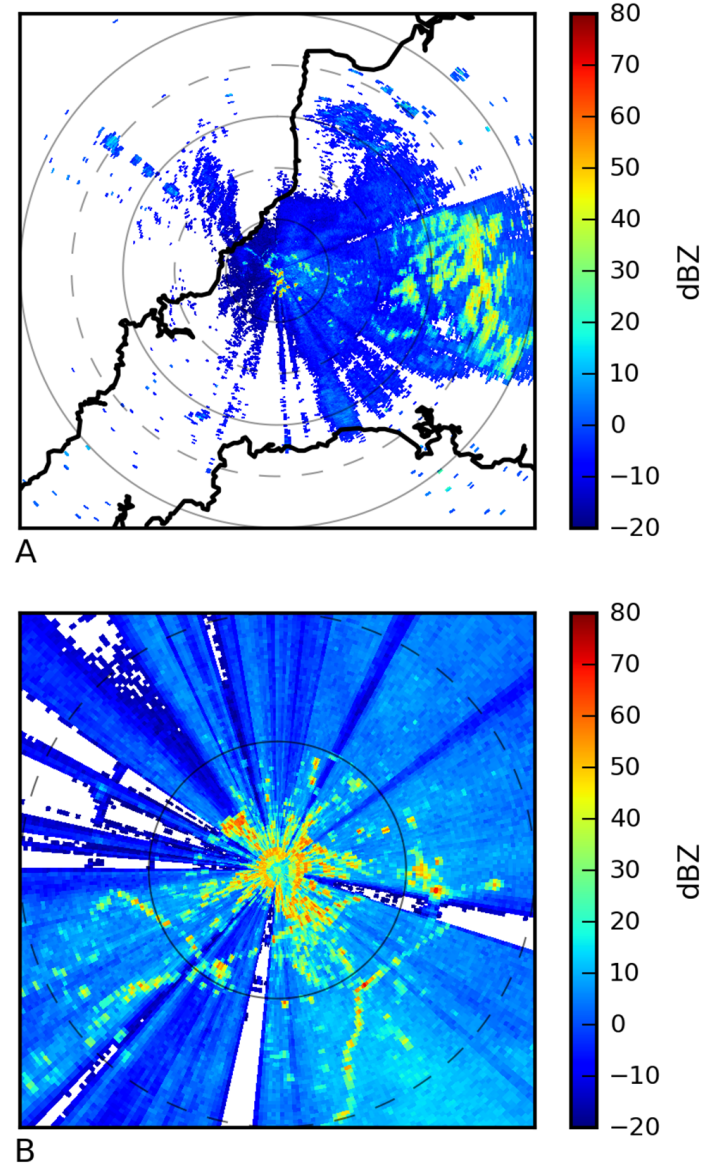

Figure 2. Identifiable ground clutter, shown here in the unfiltered horizontal reflectivity field, within $50 \mathrm{~km}$ of Davidstow (a), with range rings every $10 \mathrm{~km}$ and within $10 \mathrm{~km}$ of Burn (b), with range rings every $5 \mathrm{~km}$.

maining, useful, data. In this study, the filter identifies spurious radar echoes and passes through precipitation data for further correction routines. It is also possible to invert the filter, thereby retaining spurious data for further investigation. This is likely to be of most interest with the biological scatterers identified by the filter. Echo identification is achieved using a fuzzy logic classification scheme, applying direct and secondary dual polarisation radar moments and beam geometry.

\subsection{Defining classification parameters}

Fuzzy logic filtering requires membership functions to be defined which identify the features to be classified, with each radar parameter requiring a separate function. In addition to the dual polarisation moments available directly from the radar processing software, texture parameters have also been used in this study to provide additional information to the fuzzy classifier. All of the parameters used for classification are defined in Table 2. To define membership functions, ex- 
Table 2. Fuzzy logic parameters used in the classification scheme.

\begin{tabular}{lll}
\hline Parameter & & Units \\
\hline Uncorrected horizontal radar reflectivity & $\mathrm{dBuZ}$ & $\mathrm{dBZ}$ \\
Texture of horizontal radar reflectivity & $\sigma(Z)$ & $\mathrm{dBZ}$ \\
Differential radar reflectivity between $\mathrm{H} \& \mathrm{~V}$ & $Z_{\mathrm{DR}}$ & $\mathrm{dB}$ \\
Texture of differential radar reflectivity & $\sigma\left(Z_{\mathrm{DR}}\right)$ & $\mathrm{dB}$ \\
Cross polar correlation coefficient & $\rho_{\mathrm{HV}}$ & - \\
Texture of cross polar correlation coefficient & $\sigma\left(\rho_{\mathrm{HV}}\right)$ & - \\
Texture of differential phaseshift between $\mathrm{H} \& \mathrm{~V}$ & $\sigma\left(\Psi_{\mathrm{DP}}\right)$ & $\circ$ \\
Height of radar beam centre above sea level & $\mathrm{H}$ & $\mathrm{m}$ \\
\hline
\end{tabular}

amples of typical spurious echoes (and precipitation) were identified using expert inspection of the polar data, crosschecked with field observations.

\subsubsection{Radial texture parameters}

Texture parameters are frequently used in fuzzy logic classification schemes, particularly for the removal of spurious echoes. The majority of texture fields derived use a $3 \times 3$ (range gates by azimuth sector) or larger moving window (Chandrasekar et al., 2013), and compute either the SD or root mean square difference within this window to obtain texture. Texture parameters for the present classification are defined using a radial window of seven range gates length by one azimuth step width producing a 1 degree by 1 kilometre moving window. A similar window has been shown to be successful by Cho et al. (2006), who used the parameter for $1 \mathrm{~km}$ classifications. We chose this method of calculating texture parameters in order to retain the finer resolution of the radar observations to allow further processing at maximum polar resolution. The SD for this window then defines the texture for the central point (Eq. 1). As many other radar error sources operate along the radials of the collected data (partial beam blockage for example), the use of this radial window prevents these effects influencing the surrounding data.

As previously noted by Gourley et al. (2007), texture parameters exhibit a range-dependent structure as a result of increasing sample volume due to beam spreading. To allow the universal application of derived membership functions it is necessary to correct for this range-dependent behaviour. Correction has been achieved by inverting a third order polynomial fitted to the range average texture over a period of 12 scans from the 17 August 2013. This date was chosen as radiosonde soundings place the zero degree isotherm at $4 \mathrm{~km}$ elevation, reducing the chances of mixed-phase echoes biasing the range averaged texture of the lowest elevation scan. The polynomial is then used as a multiplicative correction factor beyond a fixed range of $25 \mathrm{~km}$ for $\sigma\left(Z_{\mathrm{DR}}\right)$ and $\sigma\left(\Psi_{\mathrm{DP}}\right)$ and $45 \mathrm{~km}$ for $\sigma\left(\rho_{\mathrm{HV}}\right)$. Figure 3 shows an example of range corrected texture of differential reflectivity, including the correction polynomial. The texture of both differential phase shift and cross-correlation coefficient are also cor-
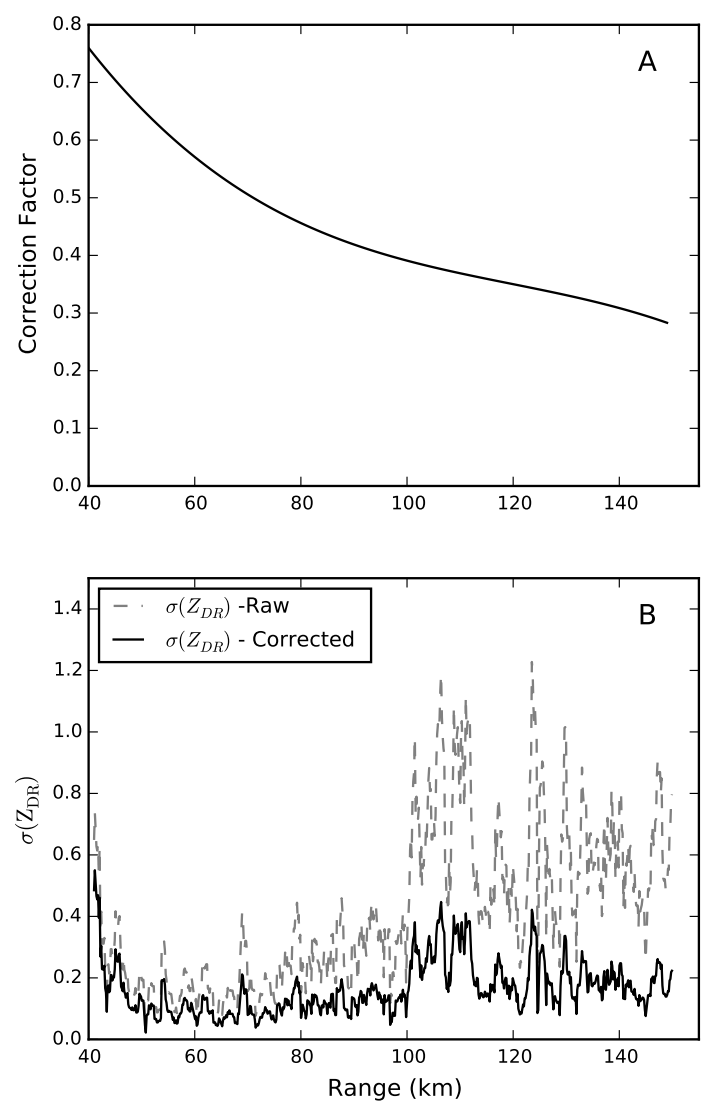

Figure 3. (a) Multiplicative correction factor used to correct $\sigma\left(Z_{\mathrm{DR}}\right)$. (b) Range variance of $\sigma\left(Z_{\mathrm{DR}}\right)$ along the $281^{\circ}$ azimuth for the 17 August 2013, 09:11:04 UTC volume scan at $0.5^{\circ}$ elevation, Davidstow deployment site. Dashed line is before correction and solid line is corrected texture as used in the fuzzy logic classifier.

rected using the same approach.

$\sigma\left(x_{r}\right)=\sqrt{\frac{1}{N-1} \sum_{i=-(N-1) / 2}^{(N-1) / 2}\left(x_{r+i}-\bar{x}\right)^{2}}$.

\subsubsection{Precipitation}

Data from 20 operational rain gauges located within $50 \mathrm{~km}$ of the Davidstow site have been used to validate expert identification of rainfall echoes from 13 scans (1-hour's data collection) from the 5 August 2013. The 0.5 and $1.5^{\circ}$ elevations from these scans were then used to construct unit normalised kernel density estimates (kdes) for each of the eight classification parameters. These are summarised, along with the non-meteorological classes in Fig. 4. As expected these show the typical dual polarisation signatures of liquid precipitation with $\rho_{\mathrm{HV}}$ greater than 0.9 and $Z_{\mathrm{DR}}$ between 0 and $5 \mathrm{~dB}$. The texture fields show low variability within precipitation, which will be useful in providing greater discrimination from 

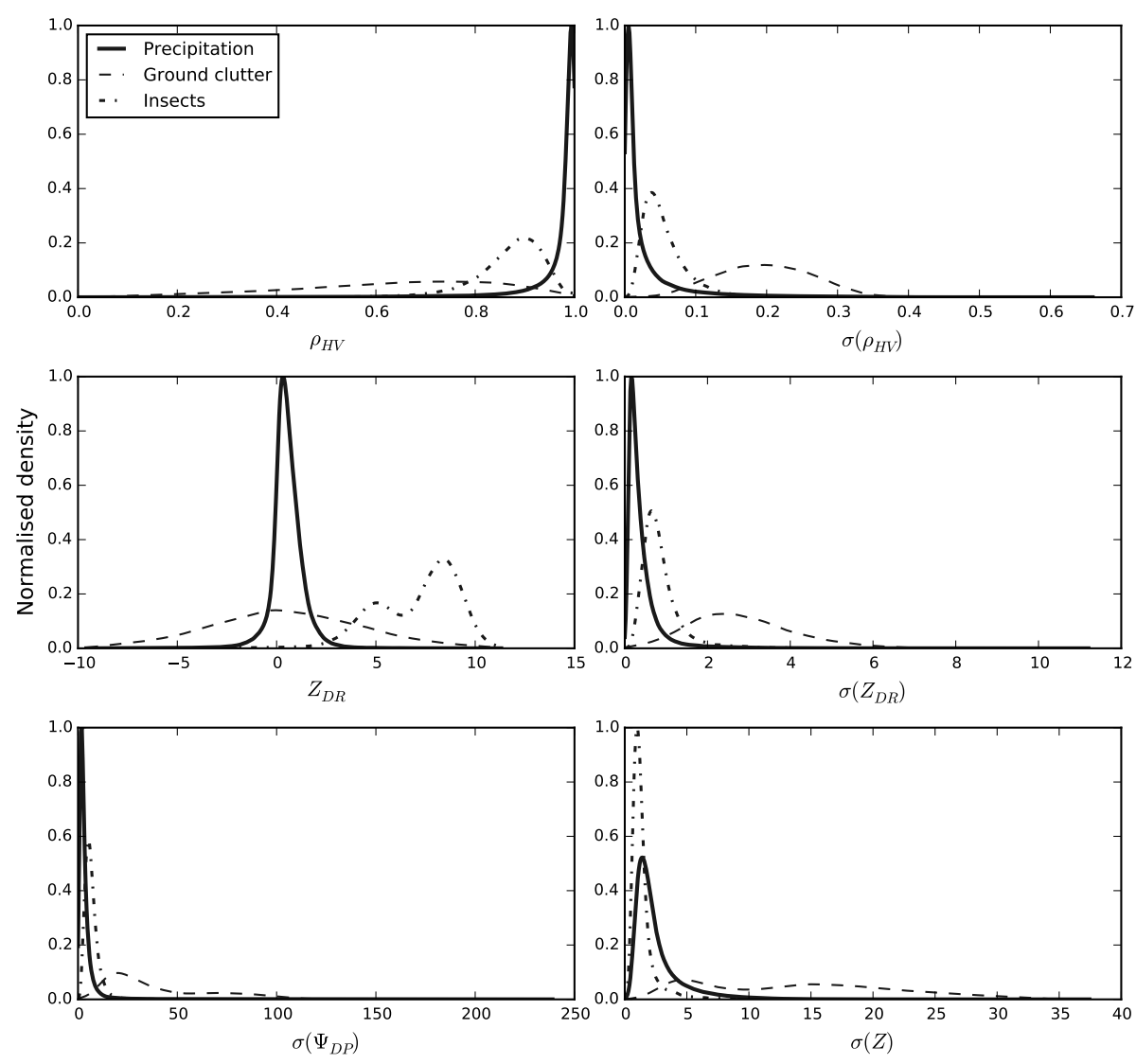

Figure 4. Class normalised histograms for the dual-polarisation and texture parameters used in this study. Classes are precipitation (solid line), ground clutter (dashed line) and insects (dash-dot line). The histograms are derived from expert identification of radar echoes using data from the COPE campaign.

non-meteorological scatterers in the fuzzy membership classification.

\subsubsection{Ground clutter}

Normal propagation condition ground clutter is the easiest spurious echo to identify, especially once a reference period of radar data is available. Statistical analysis of multiple radar scans easily identifies range gates affected by ground clutter as noted by Harrison et al. (2014). Using the COPE data set, cross-checked with elevation data and national mapping, to build a statistical mask, 26 radar scans from the 18 July 2013 (dry day) and 17 August 2013 (stratiform rainfall) were analysed to produce normalised kernel density estimates for the classification parameters. Greatest discrimination between ground clutter and precipitation is found in the texture fields, particularly $\sigma\left(\rho_{\mathrm{HV}}\right)$. It is worth noting that $\rho_{\mathrm{HV}}$ values extend across a wide range and overlap with precipitation, although not as much as in previous studies such as Zrnić et al. (2006). This difference is down to the shorter wavelength and faster antenna speed used in this study, which reduces the expected cross correlation of ground clutter returns.

\subsubsection{Biological scatterers - insects}

The presence of biological scatters within weather radar echoes is difficult to independently verify, yet research has indicated a typical echo signature can be observed. Insect echoes typically have low reflectivity ( $0-15 \mathrm{dBZ})$, high $Z_{\mathrm{DR}}$ $(>3 \mathrm{~dB})$ and low $\rho_{\mathrm{HV}}(0.3-0.6)$ (Chilson et al., 2012; Zrnić and Ryzhkov, 1998; Mueller and Larkin, 1985). Expert identification indicates a large concentration of insect returns on the 18 July 2013, a warm day with morning temperatures in excess of $24^{\circ} \mathrm{C}$, a moderate onshore breeze and rainfall restricted to isolated locations in the afternoon. Using 13 scans (1-hour's data collection) unit normalised kdes were again constructed (Fig. 4, dash-dot lines). The $Z_{\mathrm{DR}}$ observations also show a bimodal distribution above $4 \mathrm{~dB}$, which has been attributed to the two preferred orientations of insect flight (Mueller and Larkin, 1985). The $\rho_{\mathrm{HV}}$ signature from these observations lies between 0.7 and 1 , higher than previously shown by most other studies. This may be indicative of a highly uniform insect population, which exhibits little variation given the short dwell time of the radar scan strategy. A similarly high region of $\rho_{\mathrm{HV}}$ was detected by Bachmann and Zrnić (2007) when distinguishing between insect 
and bird echoes. The observed texture parameters lie between those of precipitation and ground clutter, with the exception of $\sigma(Z)$ which has a very defined signature of less than $3 \mathrm{dBZ}$.

\subsubsection{Clear air echoes and the background noise signature}

Radars often observe echoes from clear air, which can not be attributed to precipitation or biotic scatterers. These clear air echoes are attributed to changes in the refractive index of the atmosphere (Wilson et al., 1994; Lane, 1969), and are most often observed close to the radar where the absolute received power is greater. In addition to these echoes, the atmosphere typically has a background radiation signature. The X-band radar used in this study uses a passive scan to set a zero level for environmental noise, repeated at regular intervals. At times environmental conditions change such that the noise level increases in this intermittent period and though very low reflectivities are observed at these times it is simple to identify these echoes along with clear air echoes and remove them using a classification set. Histograms for noise have been omitted from Fig. 4 for clarity but those computed show noise echoes have very low texture of reflectivity ( $<1 \mathrm{dBZ})$ and cross correlation coefficient $(<0.7)$, yet a very high texture of $\Psi_{\mathrm{DP}}\left(>30^{\circ}\right)$.

\subsection{Fuzzy logic membership filtering}

Having defined the parameter ranges of the desired filtering classes, a filtering scheme has been implemented using fuzzy logic to combine the available parameters to classify the radar echoes. Firstly we defined membership functions for each class and parameter. These membership functions were applied to the available radar moments to generate individual parameter scores, which were then combined to a single fractional total. Defuzzification of the fractional totals was achieved by selecting the class with the maximum fractional score provided a certainty threshold was crossed. Once identified, meteorological echoes were then retained by the filter and despeckled to remove isolated range gates that passed through the filter. This filter has been applied to the COPE field data set, examples from which are shown in Sect. 4. The process can also be run in real time, taking less than $30 \mathrm{~s}$ per radar volume (10 elevation scans), making it suitable for real-time application in future field deployments.

\subsubsection{Variable vertex membership functions}

Typical fuzzy logic membership functions are often triangular and trapezoid in shape or defined by a centrally peaked decaying function. For this filter a variable vertex membership scheme has been implemented, which allowed variation of the membership functions' form for different parameters and classes. Between vertices linear interpolation was used to define the membership function. The minimum number

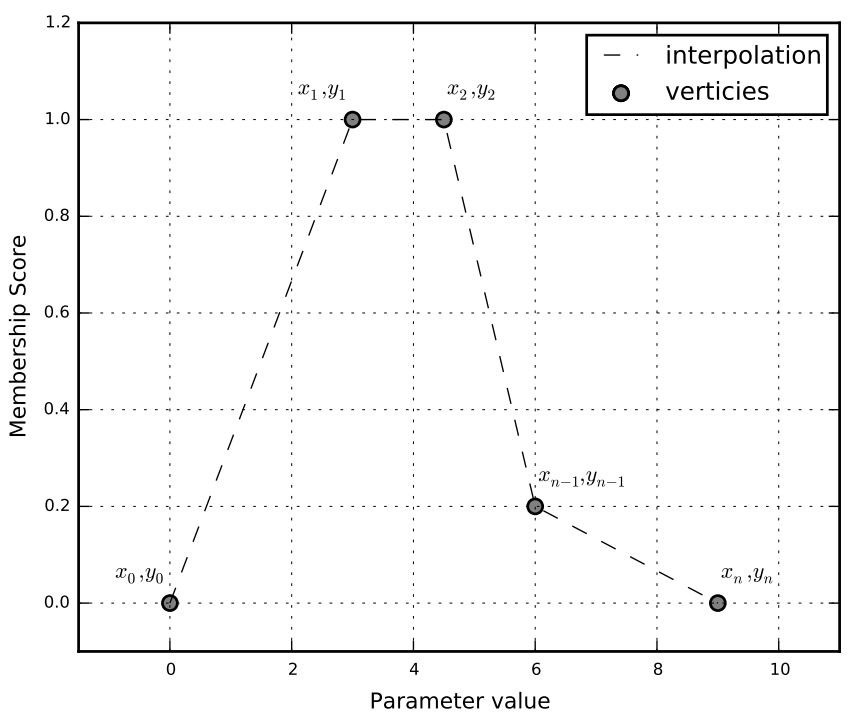

Figure 5. Example of the multiple vertex membership function approach, with vertices in the range 0 to $n$. Grey points represent vertices defining the membership function, with the dashed line indicating the interpolation between those points.

of vertices required for the function to operate is two, defining the parameters' limits $\left(x_{0}\right.$ and $\left.x_{n}\right)$ and the membership score at those limits $\left(y_{0}\right.$ and $\left.y_{n}\right)$. Outside of these limits the membership score is always zero. An example of this approach is shown in Fig. 5. The approach allows greater flexibility in the membership functions, and incorporates parameter weighting in the individual scores themselves. See Tables A1-A4 in the Appendix for all the membership vertices used in this study. During the analysis it was found that using equally weighted membership functions (maximum score of 1) was no less effective than using variable weighting optimised with a genetic algorithm. Ultimately the most parsimonious set of variables was chosen for each class. This was tested using a validation set of problem cases, where identification was deemed to be challenging, including rainfall signals mixed with wind farm ground clutter and convection embedded within probable insect returns.

\subsubsection{Combination and defuzzification}

The total fuzzy membership score for each class $(F(x))$ is calculated using

$F(x)=F(x)_{K} \times F(x)_{J}$,

where

$F(x)_{J}=\sum_{j \in J} M(x)_{j}$

and

$F(x)_{K}=\prod_{k \in K} M(x)_{k}$. 
Individual membership scores $(M(x))$ for each parameter are calculated using the defined variable vertex membership functions. Those parameters which form the additive group $(J)$ have their totals summed to calculate the additive total $\left(F(x)_{J}\right)$. Those parameters in the multiplicative threshold switch set $(K)$ conversely have their totals multiplied together to calculate their total $\left(F(x)_{K}\right)$. These two totals are then multiplied together to calculate the final class score $(F(x))$. The multiplicative threshold parameters are used to suppress certain classifications based on observational constraints, such as ground clutter being suppressed where normal beam height exceeds $2 \mathrm{~km}$ or insects where $Z_{\mathrm{DR}}$ is below $0.5 \mathrm{~dB}$. This is in contrast to the post classification decision suppression employed in other classification schemes (Gourley et al., 2007, for example). The total score $(F(x))$ is then converted to a fraction of the maximum possible score obtainable for that class. Classification is assigned to the class with the highest fractional score, provided the fractional score exceeds a predetermined certainty threshold $(0.25$ in this case). Threshold exceedance prevents uncertain range gates from being classified based on very low total class scores, instead marking these cells as unknown echo type. Once echo classification is complete, the new classification field is used for filtering of the radar data. In the following examples, the filter has been set to pass through only echoes identified as precipitation, though the inverse is also possible depending on the final application of the data.

\subsubsection{Despeckling using connected component analysis}

The final stage of the filtering in this work is to despeckle the resulting filtered fields. By application of connected component analysis (with 8 connectivity) (Dillencourt et al., 1992), independently connected areas of rainfall are identified, and those smaller than five range gates in size are removed. This approach removes regions that are unlikely to be precipitating rain cells due to their small size (no more than $1.6 \mathrm{~km}^{2}$ at the extreme limit of the radar). This is similar to the nearest neighbour count approach used in other schemes, but has the advantages of retaining connectivity on the edge of large cells and of not reclassifying range gates surrounded by a different classification, which can be a reasonable outcome in the case of point target clutter for example.

\section{Application of the filter}

The prescribed filter has been applied retrospectively to all the data collected during the COPE field campaign, and has also been applied to subsequent deployments of the radar at the Burn field site. The following examples show its benefits for both qualitative and quantitative analysis of the radar data.
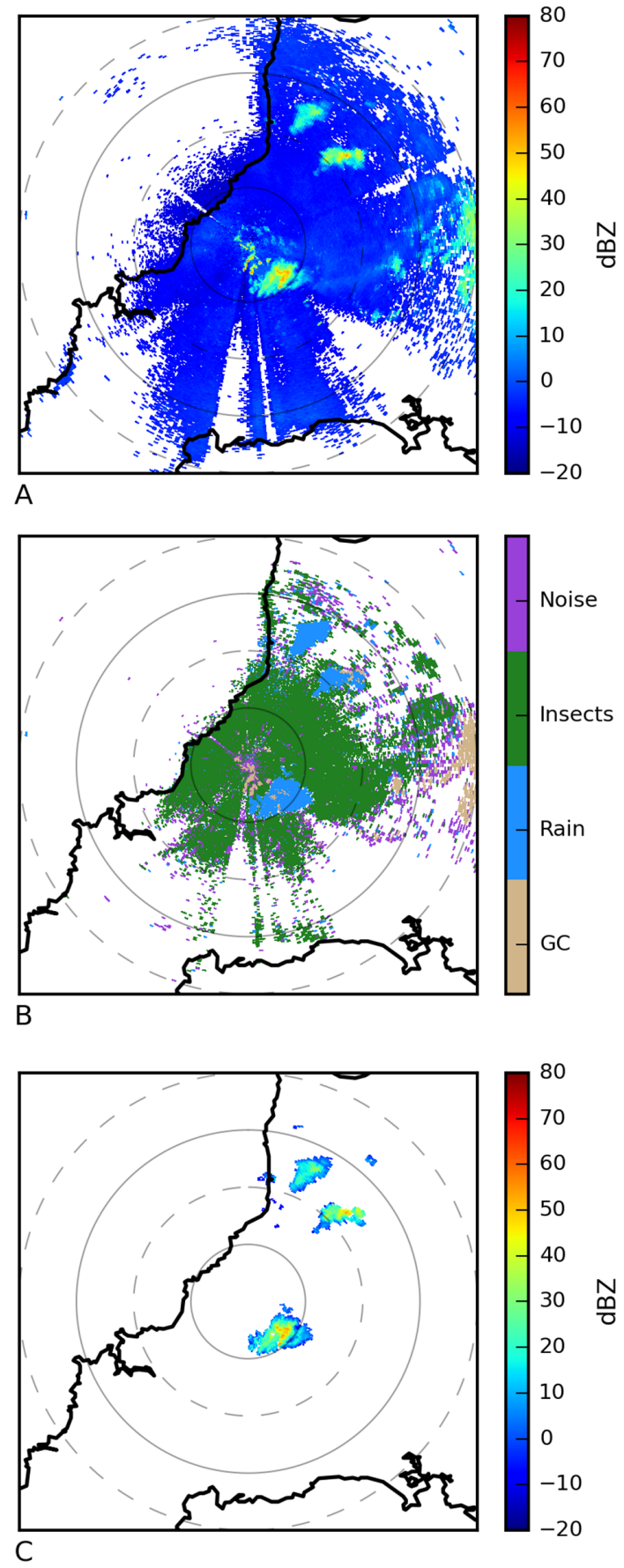

Figure 6. Application of fuzzy logic classifier to $0.5^{\circ}$ elevation scan, 18 July 2013, 14:15 UTC. (a) shows the uncorrected horizontal reflectivity, (b) the results of applying the fuzzy classifier and (c) the filtered reflectivity from those echoes identified as rainfall. Range rings are at $10 \mathrm{~km}$ intervals. 


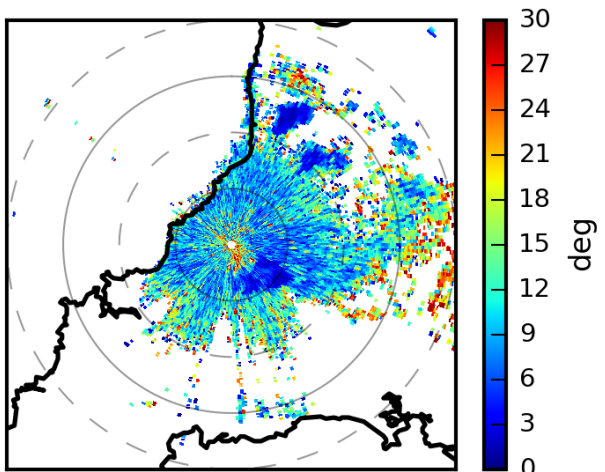

A

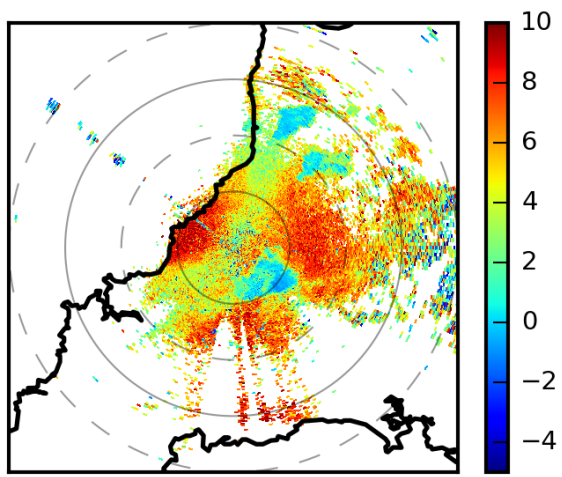

C

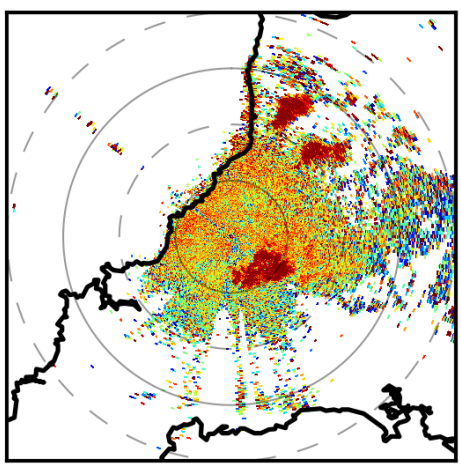

E

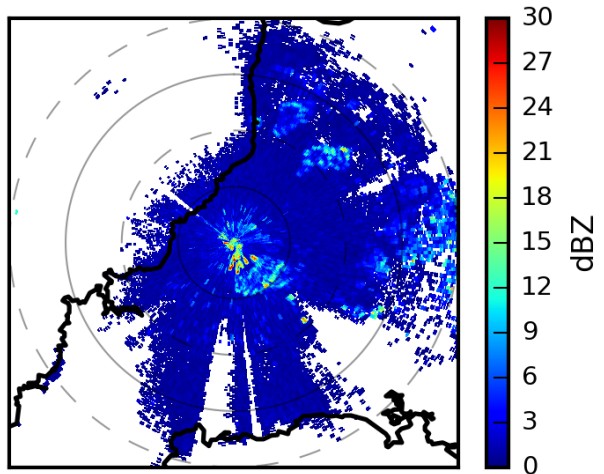

B

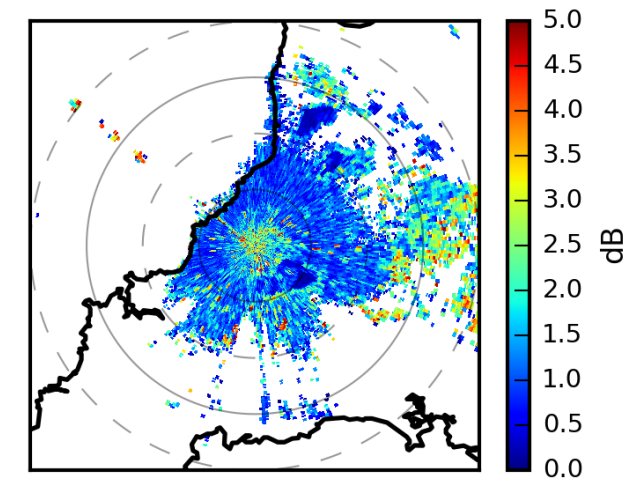

D

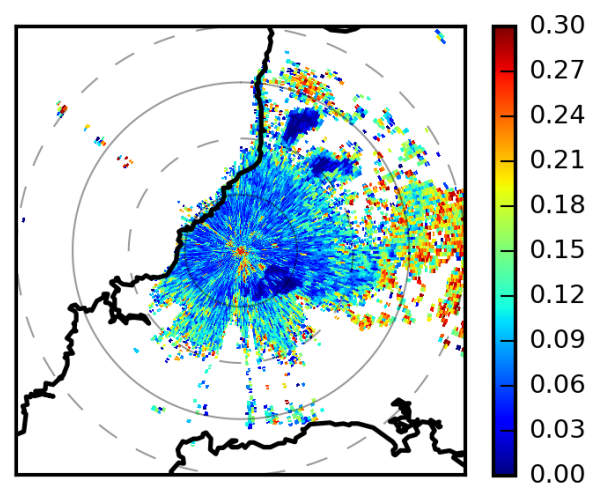

$\mathrm{F}$

Figure 7. Radar parameters used for the classification of Fig. 6. (a) shows $\sigma\left(\Psi_{\mathrm{DP}}\right),(\mathbf{b}) \sigma(Z),(\mathbf{c}) Z_{\mathrm{DR}},(\mathbf{d}) \sigma\left(Z_{\mathrm{DR}}\right),(\mathbf{e}) \rho_{\mathrm{HV}}$ and $(\mathbf{f}) \sigma\left(\rho_{\mathrm{HV}}\right)$.

\subsection{Example 1: convection embedded within biological scatterers}

The first example presented here is from 18 July 2013. With daytime temperatures in excess of $20^{\circ} \mathrm{C}$ driving an onshore sea breeze, convective showers eventually developed during the afternoon, breaking through a stable boundary layer. Rain gauges observed only two isolated events during the day, with accumulations of $0.2 \mathrm{~mm}$ recorded at two gauges. Figure 6 shows a snapshot of these isolated convective showers, two to the north-east and one to the south of the radar, embedded within a strong clear air signal prevalent across the radar sweep. The application of the fuzzy classifier identifies the three convective showers, using the parameters shown in Fig. 7, while also identifying ground clutter signals from Dartmoor to the east and local topography around the radar. By passing through only the precipitation echoes identified by the fuzzy classifier a much clearer picture of the convective showers is available, as shown in Fig. 6c. From Fig. 7 it is clear that the cells are identifiable in all of the parameters shown, with the textures of $\Psi_{\mathrm{DP}}$ and $\rho_{\mathrm{HV}}$ being particularly indicative. These convective cells extended up to 10 kilometres in altitude, with reflectivity in excess of $50 \mathrm{dBZ}$ 
and differential reflectivity over $6 \mathrm{~dB}$ in the cores, indicating very large rain drops in places. It should be noted that the fringes of these cells are generally unclassified by the filter due to the certainty threshold, which is due to a combination of elevated linear textures at the margins of strong convective cells and also low reflectivity. Although identifiable, the non classification of these range gates is negligible for both data assimilation, where data certainty is critical and for QPE, where the reflectivity values indicate near-zero rainfall intensities.

\subsection{Example 2: frontal rainfall traversing the radar}

A second example is the traversal of light rainfall across the radar, and more importantly, local ground clutter targets. In this situation the rainfall dampens the signal from the ground clutter, but there is still an elevated reflectivity signal due to its presence. On 17 August 2013 a frontal system moved across the Cornish peninsula during the day, with widespread light rainfall (6-13 $\mathrm{mm}$ in $12 \mathrm{~h}$ ) recorded across the region by the rain gauge network. Figure 8 shows the filter removing ground clutter within $10 \mathrm{~km}$ of the radar, despite the mixed signals from the rainfall and ground clutter. These mixed signal echoes are often the most difficult to process, and there is evidence of some clutter signals passing through the filter on the fringes of the stronger returns and where the contrast between clutter and rainfall reflectivity is minimal (such as over the wind farm located due east of the radar at about $5 \mathrm{~km}$ range).

\subsection{Example 3: COPE total rainfall accumulations}

The long-term benefits of spurious echo removal are illustrated by total rainfall accumulations during COPE. Rainfall intensities for all scans can be calculated, in a first instance, through use of the Marshall-Palmer relation, taking the standard coefficients as used in the UK operational radar network (Harrison et al., 2012):

$Z=200 R^{1.6}$.

Although more complex algorithms now exist for the calculation of rainfall using dual polarisation weather radar, this simple approach highlights the quantitative benefits of the fuzzy logic filtering, prior to any further corrections (such as for attenuation and beam blockage). Through application of the filter, excessive estimated rainfall totals resulting from elevated reflectivity from ground clutter are removed, reducing total rainfall accumulations. These reductions better match those areas unaffected by spurious echoes, with the total accumulation bias at the St Clether rain gauge, located within the wind farm to the east of the radar, reducing from 8.72 to 0.33 for the $0.5^{\circ}$ elevation. This represents a shift from severe overestimation due to clutter to a conservative accumulation of rainfall due to the certainty thresholds in the classifier and
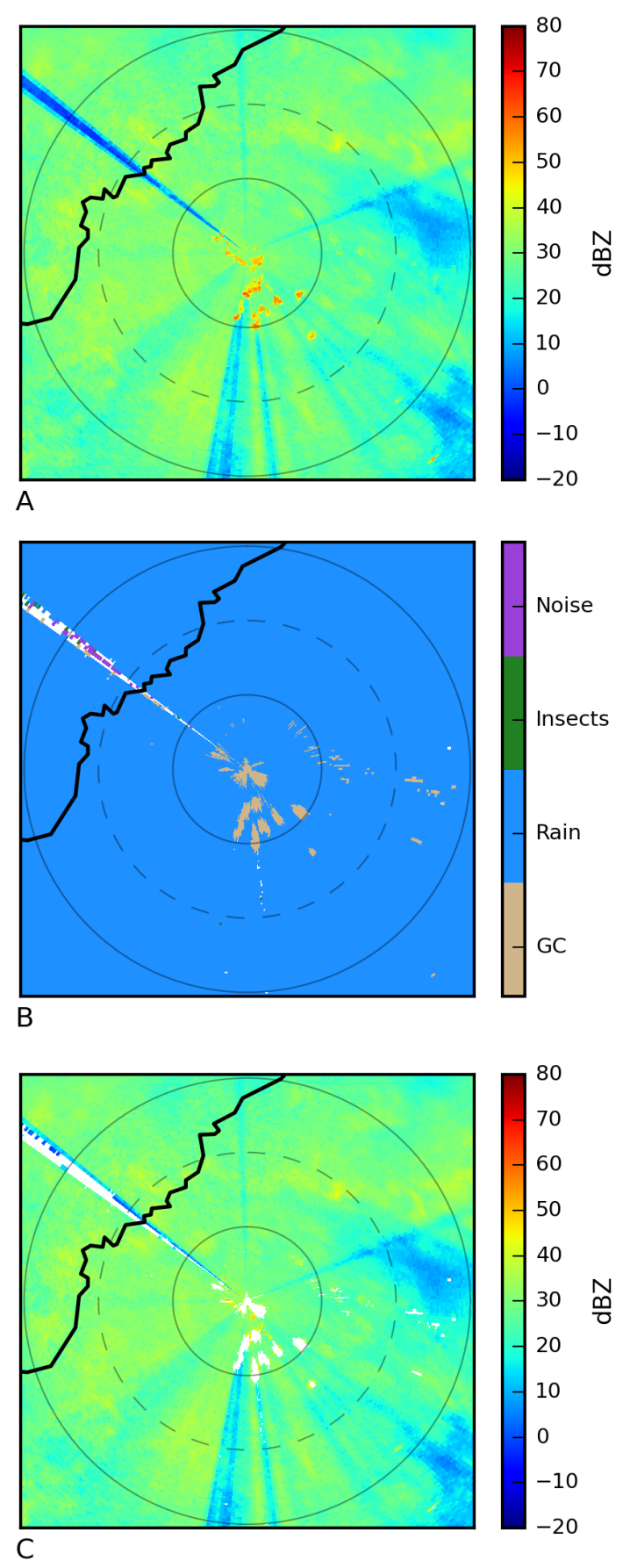

Figure 8. Application of fuzzy logic classifier to $0.5^{\circ}$ elevation scan, 17 August 2013, 11:57 UTC. (a-c) as for Fig. 6. Range rings are at $5 \mathrm{~km}$ intervals.

the complexity of the wind farm as a dual source (clutter and rain) target. Nineteen additional rain gauges across the Cornish peninsula were used to provide additional verification of the filter, and show non-meteorological echoes to be an insignificant error source for their locations. All of the rain gauges show a systematic under measurement by the radar 

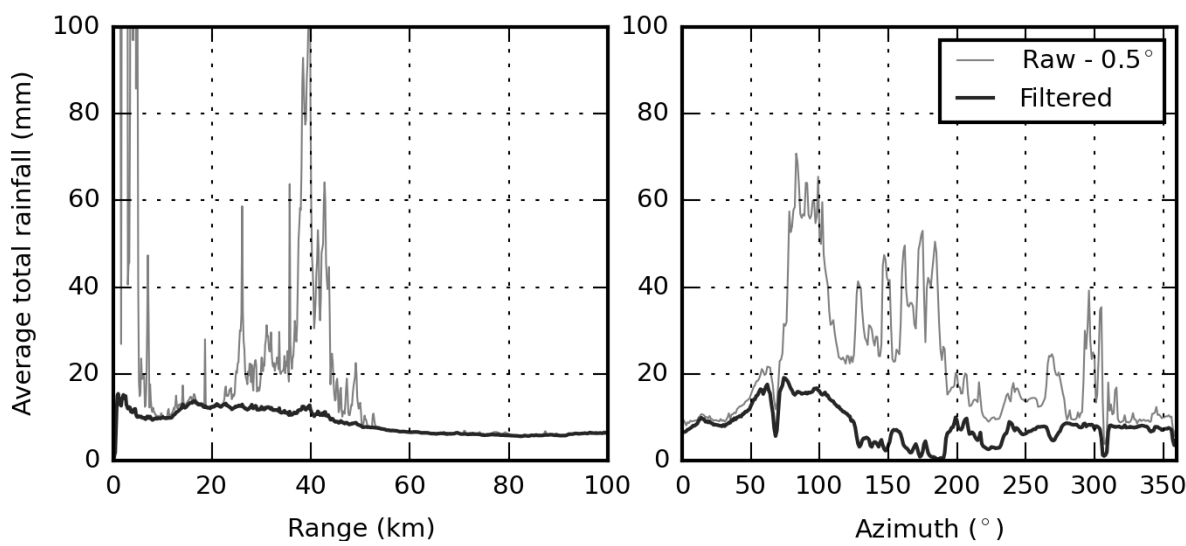

Figure 9. Range- and radially-averaged total rainfall totals for the COPE project. Grey lines show the original data, while black lines are after the application of the clutter filter. Both show the $0.5^{\circ}$ elevation scan results. The average accumulation for rain gauges in the area was $27.21 \mathrm{~mm}$.
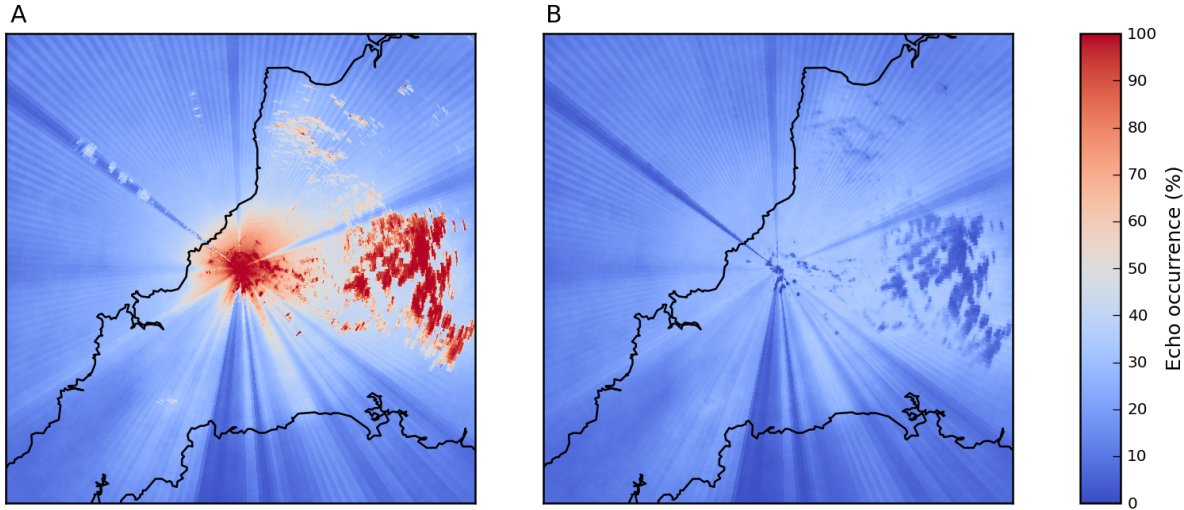

Figure 10. Percentage of times each range gate contains a measurable reflectivity echo during the COPE campaign (1132 scans total). Plots are to $50 \mathrm{~km}$ range for the lowest, $0.5^{\circ}$, elevation scan. (a) shows the raw reflectivity, while (b) shows only those echoes identified as rainfall by the filter.

due to as yet uncorrected beam blockage, attenuation and beam overshooting. At these locations the filter reduces the radar accumulations by less than 2 percent for 13 of the sites and between 3 and 13 percent for the remaining six sites, showing that the filter does not systematically remove precipitating echoes.

The range-averaged rainfall totals shown in Fig. 9 highlight the impact of the near-field clutter seen in Fig. 8, out to $10 \mathrm{~km}$, and also the impact of Dartmoor at $40 \mathrm{~km}$. After filtering these effects are removed, with the new profile reflecting the expected range decrease of radar derived accumulation as the beam widens and overshoots rainfall. In contrast the azimuthally averaged data seen in Fig. 9 is more interesting. The sharp spikes in the original data are a result of the local topography, including Dartmoor at $90-100^{\circ}$. There is also strong evidence of partial beam blockage, which becomes more evident in the filtered data between 160 and $200^{\circ}$ (due to Bodmin Moor and Davidstow woods) and at $305^{\circ}$ (due to the airfield control tower). The underlying trend indicates an increase in accumulation inland, towards the higher topography to the east.

Accumulated rainfall statistics for the campaign also highlight the benefit of the filter. Prior to filtering, echoes occur in over $90 \%$ of low-elevation scans in those range gates associated with high topography (Fig. 10), while a zone of above average number of observed echoes occurs within $20 \mathrm{~km}$ of the radar, closely mirroring the coastline to the north-west of the radar, which is indicative of a high occurrence of biological scatterers. After filtering these features are removed, with echoes occurring around $40 \%$ of the time, except in regions of beam blockage and where ground clutter dominates the radar reflectivity observations.

\subsection{Example 4: near field clutter at a new deployment site}

The final example is taken from a second deployment location within the UK. The Burn field site is an occasional testing site for the radar. On 6 October 2014 the radar was de- 


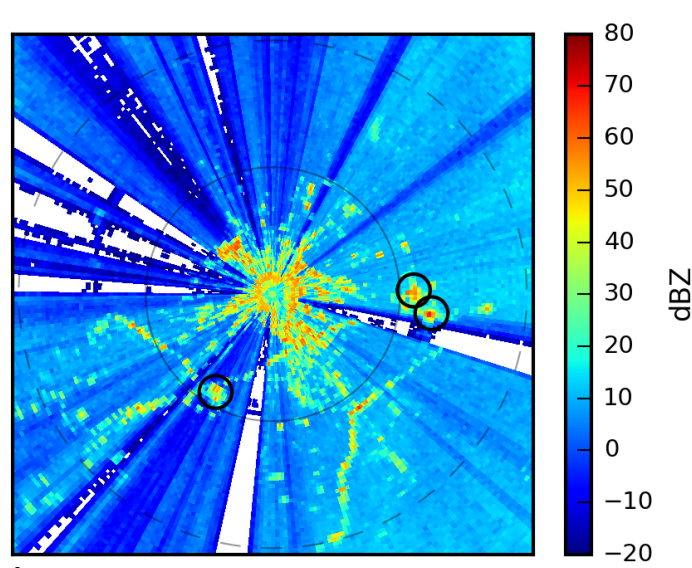

A
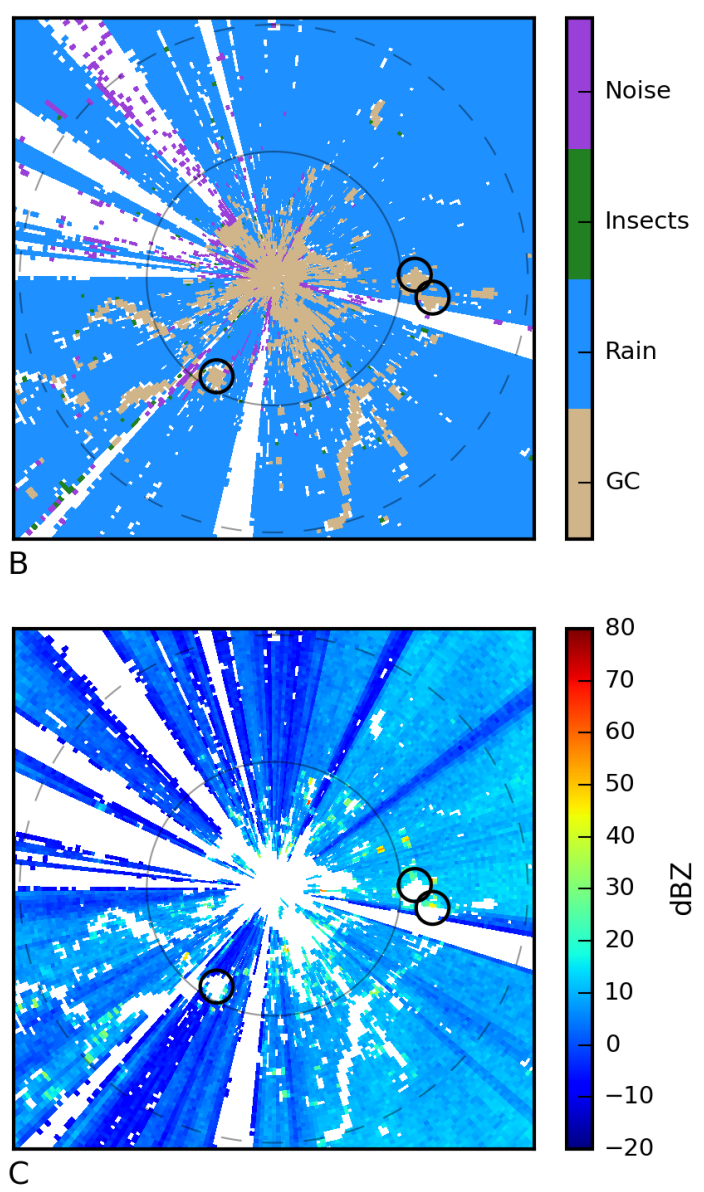

Figure 11. Application of fuzzy logic classifier to $0.5^{\circ}$ elevation scan, 6 October 2014, 12:01 UTC from Burn field deployment site. (a-c) as for Fig. 6. Range rings are at $5 \mathrm{~km}$ intervals. Local clutter is a combination of trees, topography and power infrastructure. Three sets of cooling towers from two power stations are ringed with black circles.

ployed to observe the passage of a low pressure system across the UK. The system brought persistent rainfall and strong winds. The Burn site suffers from severe ground clutter at low elevations, as shown by the $0.5^{\circ}$ scans shown in Figs. 2 and 11. Figure 11 indicates the success of the fuzzy filter in removing these spurious echoes, even those caused by small features such as power lines and individual clusters of power station cooling towers, shown by the black rings. The filter applied is based on the membership functions derived from prior observations, with no adjustment for the change in field site, indicating that the filtering methodology is dependent on the scan parameters used (such as pulse width and range spacing) rather than the location in which the radar is deployed, at least within a similar climatic region. During long field deployments it would be advantageous to monitor the performance of the filter and re-calibrate the membership functions to be specific to the nuances of the site, such as the point features identifiable around Burn.

\section{Summary and conclusions}

The identification and removal of spurious echoes from radar data has clear benefits for both visualising weather systems and quantitative analysis of those systems, including further post-processing of data to correct for other error sources. The methodology outlined here uses both primary dual polarisation moments and secondary texture fields, along with beam height to drive a fuzzy logic classifier to identify ground clutter, insects and background noise. The main advantages of this approach are:

- Fuzzy logic provides a dynamic classification that adjusts to changing atmospheric conditions and can be run in near-real time.

- The approach only requires a limited sample of training data to produce successful results, as shown here by the use of 13-26 scans per echo type.

- The multi-vertex membership functions used are highly adaptable, allowing differing distributions to be specified for the range of parameters used in the scheme, while also allowing easy addition of future variables and echo types.

This approach successfully identifies, and therefore filters, the majority of echoes as shown by the four examples presented here. The variety of examples highlights the adaptability of the approach, and from these examples the following conclusions become evident:

- Static ground clutter is identified successfully, both in the near field region and at longer ranges (Dartmoor, for example). This is most evident in the long-term rainfall accumulation from the COPE field campaign.

- Insect classification is strongly influenced by the dualpolarimetry moments available, particularly $Z_{\mathrm{DR}}, \rho_{\mathrm{HV}}$ and $\sigma\left(\rho_{\mathrm{HV}}\right)$ as the insect signatures differ from those 
of rain and ground echoes. The other texture parameters provide less value here, but are vital for distinguishing between rain, ground echoes and background noise.

- The fringes of convective cells are often misclassified as noise, insects or left unclassified due to the threshold filter. As these echoes are typically below $10 \mathrm{dBZ}$ the impact on precipitation estimates is minimal, but the effect should be noted for process studies of cell evolution and extent.

- Deployment at a second field site (Burn) shows that the method is transferable, without recalibration of the membership functions, provided the scan parameters are similar and the local climate does not vary greatly.

- The Burn site also indicates the classifier is able to identify small-scale clutter features such as the evident power lines seen within $5 \mathrm{~km}$ of the radar.

- A longer period of data needs to be analysed to fully evaluate the scheme, particularly to identify any systematic biases in classification and assess performance in winter conditions, where ice phase hydrometeors are more likely. More data will also allow a comparison with more data intensive, fully autonomous methodologies, which could yield interesting insights into their applicability.

- Beam propagation errors are clear within the data and should be corrected for before any meaningful rainfall comparisons can be computed, these include partial beam blockage due to the local clutter and also attenuation effects, which are clearly visible in the 18 July example.
The methodology presented here is applicable to not only $\mathrm{X}$-band but also C- and S-band dual polarisation radars, with the only requirement being training data with which to develop the membership functions. The use of fuzzy logic provides the dynamic filtering necessary to deal with transient spurious echoes such as anomalous propagation ground clutter and biological scatterers, while other phenomena should be equally detectable given sufficient training data (such as chaff). The methodology also allows for expansion to include a more complete hydrometeor classification, which will be explored in future work. The texture fields presented here will be of great value in such a classification, alongside the standard radar moments available. Future analysis of the data will also focus on the benefits of correcting for beam propagation errors, particularly attenuation, given its impact on short wavelength radar. 


\section{Appendix A}

Table A1. Precipitation membership functions.

\begin{tabular}{lll}
\hline Parameter & Parameter vertices & Membership vertices \\
\hline$\sigma\left(Z_{\mathrm{DR}}\right)$ & $0,1,5$ & $1,0.1,0$ \\
$\rho_{\mathrm{HV}}$ & $0.9,0.94,0.98,1.0$ & $0,0.4,1,1$ \\
$\sigma\left(\rho_{\mathrm{HV}}\right)$ & $0,0.05,0.1$ & $1,0.1,0$ \\
$\sigma\left(\Psi_{\mathrm{DP}}\right)$ & $0,6,20$ & $1,0.2,0$ \\
\hline $\mathrm{dBuZ}$ & $-11,-10,100,101$ & $0,1,1,0$ \\
\hline
\end{tabular}

Table A2. Ground clutter membership functions.

\begin{tabular}{lll}
\hline Parameter & Parameter vertices & Membership vertices \\
\hline$\sigma(Z)$ & $0,5,15,40,50$ & $0,0.6,1,1,0$ \\
$\sigma\left(Z_{\mathrm{DR}}\right)$ & $0,1,3,10$ & $0,0.1,1,1$ \\
$\rho_{\mathrm{HV}}$ & $0,0.4,0.7,1$ & $0,1,1,0$ \\
$\sigma\left(\rho_{\mathrm{HV}}\right)$ & $0.05,0.2,0.4$ & $0,1,0$ \\
$\sigma\left(\Psi_{\mathrm{DP}}\right)$ & $0,20,50,100,120$ & $0,1,0.8,0.8,1$ \\
\hline $\mathrm{dBuZ}$ & $-50,10,20,200$ & $0,0,1,1$ \\
$\mathrm{H}$ & $0,1000,2000$ & $1,1,0$ \\
\hline
\end{tabular}

Tables A1-A4 may be of interest to some readers, and outline the membership functions used to identify each of the four classes within the fuzzy classifier. Those parameters given separately at the end of each table form the multiplicative set, while the remainder form the additive set.
Table A3. Noise membership functions.

\begin{tabular}{lll}
\hline Parameter & Parameter vertices & Membership vertices \\
\hline$\sigma(Z)$ & $0,0.5,1,2$ & $1,0.8,0.1,0$ \\
$\rho_{\mathrm{HV}}$ & $0,0.6,0.7,1$ & $1,0.75,0,0$ \\
$\sigma\left(\Psi_{\mathrm{DP}}\right)$ & $0,15,30,100$ & $0,0.1,1,1$ \\
\hline $\mathrm{dBuZ}$ & $-30,5,10,200$ & $1,1,0,0$ \\
\hline
\end{tabular}

Table A4. Insect membership functions.

\begin{tabular}{lll}
\hline Parameter & Parameter vertices & Membership vertices \\
\hline$\sigma(Z)$ & $0,1,2,5$ & $0.4,1,0.2,0$ \\
$\sigma\left(Z_{\mathrm{DR}}\right)$ & $0,1,2$ & $0,1,0$ \\
$\rho_{\mathrm{HV}}$ & $0.6,0.8,0.89,1$ & $0,0.5,1,0$ \\
$\sigma\left(\rho_{\mathrm{HV}}\right)$ & $0,0.05,0.1$ & $0,1,0$ \\
$\sigma\left(\Psi_{\mathrm{DP}}\right)$ & $0,8,20$ & $0,1,0$ \\
\hline $\mathrm{dBuZ}$ & $-11,-10,20,21$ & $0,1,1,0$ \\
$Z_{\mathrm{DR}}$ & $0,2,4,20$ & $0,0,1,1$ \\
\hline
\end{tabular}


Acknowledgements. We would like to thank V. Lakshmanan and the two anonymous reviewers for helping to improve the paper with their comments. We would also like to acknowledge the support of NERC for funding David Dufton during this research and also for funding the COPE field campaign (Grant no. NE/J023507/1). We would like to thank all members of the COPE team who made the data collection possible, particularly Alan Blyth for organising the campaign and Lindsay Bennett and John Nicol for their important contributions to the radar data collection and calibration. The comments of Lindsay Bennett and Ryan Neely have also been extremely valuable in improving this research. We would also like to thank the Environment Agency for providing the rain gauge data used in the study.

Edited by: G. Vulpiani

\section{References}

Bachmann, S. and Zrnić, D. S.: Spectral density of polarimetric variables separating biological scatterers in the VAD display, J. Atmos. Ocean. Tech., 24, 1186-1198, 2007.

Balakrishnan, N. and Zrnić, D. S.: Use of polarization to characterize precipitation and discriminate large hail, J. Atmos. Sci., 47, 1525-1540, 1990.

Bennett, L.: Scan data from NCAS mobile X-band radar. NCAS, British Atmospheric Data Centre, available at: http://catalogue. ceda.ac.uk/uuid/4bb383b7d6ca421bbedd57b8097d5664, last access: 14 April, 2015.

Berenguer, M., Sempere-Torres, D.,Corral, C., and SánchezDiezma, R.: A fuzzy logic technique for identifying nonprecipitating echoes in radar scans, J. Atmos. Ocean. Tech., 23, 11571180, 2006.

Blyth, A. M., Bennett, L. J., and Collier, C. G.: High-resolution observations of precipitation from cumulonimbus clouds, Meteorol. Appl., 22, 75-89, 2015.

Bringi, V. and Chandrasekar, V.: Polarimetric Doppler Weather Radar: Principles and Applications, Cambridge University Press, Cambridge, USA, 2001.

Chandrasekar, V., Keränen, R., Lim, S., and Moisseev, D.: Recent advances in classification of observations from dual polarization weather radars, Atmos. Res., 119, 97-111, 2013.

Chilson, P. B., Frick, W. F., Kelly, J. F., Howard, K. W., Larkin, R. P., Diehl, R. H., Westbrook, J. K., Kelly, T. A., and Kunz, T. H.: Partly cloudy with a chance of migration: weather, radars, and aeroecology, B. Am. Meteorol. Soc., 93, 669-686, 2012.

Cho, Y.-H., Lee, G. W., Kim, K.-E., and Zawadzki, I.: Identification and removal of ground echoes and anomalous propagation using the characteristics of radar echoes, J. Atmos. Ocean. Tech., 23, 1206-1222, 2006.

Collier, C. G.: Accuracy of rainfall estimates by radar, Part I: Calibration by telemetering raingauges, J. Hydrol., 83, 207-223, 1986.

Delrieu, G. and Creutin, J.-D.: Weather radar and urban hydrology: advantages and limitations of X-band light configuration systems, Atmos. Res., 27, 159-168, 1991.

Dillencourt, M. B., Samet, H., and Tamminen, M.: A general approach to connected-component labeling for arbitrary image representations, J. Assoc. Comput. Mach., 39, 253-280, 1992.
Dolan, B. and Rutledge, S. A.: A theory-based hydrometeor identification algorithm for X-band polarimetric radars, J. Atmos. Ocean. Tech., 26, 2071-2088, 2009.

Doviak, R. J. and Zrnić, D. S.: Doppler Radar \& Weather Observations, Academic press, London, UK, 1984.

Gourley, J. J., Tabary, P., and Parent du Chatelet, J.: A fuzzy logic algorithm for the separation of precipitating from nonprecipitating echoes using polarimetric radar observations, J. Atmos. Ocean. Tech., 24, 1439-1451, 2007.

Gourley, J. J., Illingworth, A. J., and Tabary, P.: Absolute calibration of radar reflectivity using redundancy of the polarization observations and implied constraints on drop shapes, J. Atmos. Ocean. Tech., 26, 689-703, 2009.

Grazioli, J., Tuia, D., and Berne, A.: Hydrometeor classification from polarimetric radar measurements: a clustering approach, Atmos. Meas. Tech., 8, 149-170, doi:10.5194/amt-8-149-2015, 2015.

Hall, M. P., Goddard, J. W. F., and Cherry, S. M.: Identification of hydrometeors and other targets by dual-polarization radar, Radio Sci., 19, 132-140, 1984.

Harper, W. G.: Detection of bird migration by centimetric radar a cause of radar'angels', P. Roy. Soc. Lond. B Bio., 149, 484$502,1958$.

Harrison, D. L., Driscoll, S. J., and Kitchen, M.: Improving precipitation estimates from weather radar using quality control and correction techniques, Meteorol. Appl., 7, 135-144, 2000.

Harrison, D. L., Norman, K., Pierce, C., and Gaussiat, N.: Radar products for hydrological applications in the UK, Proceedings of the ICE-Water Management, 165, 89-103, 2012.

Harrison, D. L., Georgiou, S., Gaussiat, N., and Curtis, A.: Longterm diagnostics of precipitation estimates and the development of radar hardware monitoring within a radar product data quality management system, Hydrolog. Sci. J., 59, 1277-1292, 2014.

Hubbert, J. C., Dixon, M., Ellis, S. M., and Meymaris, G.: Weather radar ground clutter. Part I: Identification, modeling, and simulation, J. Atmos. Ocean. Tech., 26, 1165-1180, 2009.

Lakshmanan, V., Fritz, A., Smith, T., Hondl, K., and Stumpf, G.: An automated technique to quality control radar reflectivity data, J. Appl. Meteorol. Clim., 46, 288-305, 2007.

Lane, J.: Radar echoes from clear air in relation to refractive-index variations in the troposphere, P. I. Electr. Eng., 116, 1656-1660, 1969

Löwe, R., Thorndahl, S., Mikkelsen, P. S., Rasmussen, M. R., and Madsen, H.: Probabilistic online runoff forecasting for urban catchments using inputs from rain gauges as well as statically and dynamically adjusted weather radar, J. Hydrol., 512, 397407, 2014.

Mariani, S., Casaioli, M., Lanciani, A., Flavoni, S., and Accadia, C.: QPF performance of the updated SIMM forecasting system using reforecasts, Meteorol. Appl., 22, 256-272, 2014.

Michelson, D., Einfalt, T., Holleman, I., Gjertsen, U., Friedrich, K., Haase, G., Lindskog, M., and Szturc, J.: Weather radar data quality in Europe: quality control and characterisation, Tech. rep., COST Action 717, 2005.

Mueller, E. A. and Larkin, R. P.: Insects observed using dualpolarization radar, J. Atmos. Ocean. Tech., 2, 49-54, 1985.

Nguyen, C. M., Moisseev, D. N., and Chandrasekar, V.: A parametric time domain method for spectral moment estimation and 
clutter mitigation for weather radars, J. Atmos. Ocean. Tech., 25, 83-92, 2008.

Park, H. S., Ryzhkov, A. V., Zrnić, D. S., and Kim, K.-E.: The hydrometeor classification algorithm for the polarimetric WSR88D: description and application to an MCS, Weather Forecast., 24, 730-748, 2009.

Plank, V. G.: A meteorological study of radar angels, Tech. rep., DTIC Document, Bedford, Massachusetts, USA, 1956.

Rauthe, M., Steiner, H., Riediger, U., Mazurkiewicz, A., and Gratzki, A.: A Central European precipitation climatology - Part I: Generation and validation of a high-resolution gridded daily data set (HYRAS), Meteorol. Z., 22, 235-256, 2013.

Rico-Ramirez, M. A. and Cluckie, I. D.: Classification of ground clutter and anomalous propagation using dual-polarization weather radar, IEEE T. Geosci. Remote, 46, 1892-1904, 2008.

Ryzhkov, A. V. and Zrnić, D. S.: Radar polarimetry at S, C, and X bands: Comparative analysis and operational implications, 32nd AMS International Conference on Radar Meteorology, Alberquerque, USA, 2005.

Sander, J., Ester, M., Kriegel, H. P., and Xu, X.: Density-based clustering in spatial databases: The algorithm gdbscan and its applications, Data Mining and Knowledge Discovery, 2, 169-194, 1998.

Seliga, T. and Bringi, V.: Potential use of radar differential reflectivity measurements at orthogonal polarizations for measuring precipitation, J. Appl. Meteorol., 15, 69-76, 1976.

Seliga, T. and Bringi, V.: Differential reflectivity and differential phase shift: applications in radar meteorology, Radio Sci., 13, 271-275, 1978.

Shao, Q., Lerat, J., Brink, H., Tomkins, K., Yang, A., Peeters, L., Li, M., Zhang, L., Podger, G., and Renzullo, L. J.: Gauge based precipitation estimation and associated model and product uncertainties, J. Hydrol., 444, 100-112, 2012.
Steiner, M. and Smith, J. A.: Use of three-dimensional reflectivity structure for automated detection and removal of nonprecipitating echoes in radar data, J. Atmos. Ocean. Tech., 19, 673-686, 2002.

Testud, J., Le Bouar, E., Obligis, E., and Ali-Mehenni, M.: The rain profiling algorithm applied to polarimetric weather radar, J. Atmos. Ocean. Tech., 17, 332-356, 2000.

Torres, S. M. and Zrnić, D. S.: Ground clutter canceling with a regression filter, J. Atmos. Ocean. Tech., 16, 1364-1372, 1999.

Villarini, G. and Krajewski, W. F.: Review of the different sources of uncertainty in single polarization radar-based estimates of rainfall, Surv. Geophys., 31, 107-129, 2010.

Wilson, J. W., Weckwerth, T. M., Vivekanandan, J., Wakimoto, R. M., and Russell, R. W.: Boundary layer clear-air radar echoes: origin of echoes and accuracy of derived winds, J. Atmos. Ocean. Tech., 11, 1184-1206, 1994.

Zadeh, L. A.: A computational approach to fuzzy quantifiers in natural languages, Comput. Math. Appl., 9, 149-184, 1983.

Zrnić, D. S. and Ryzhkov, A. V.: Observations of insects and birds with a polarimetric radar, IEEE T. Geosci. Remote, 36, 661-668, 1998.

Zrnić, D. S. and Ryzhkov, A. V.: Polarimetry for weather surveillance radars, B. Am. Meteorol. Soc., 80, 389-406, 1999.

Zrnić, D. S., Melnikov, V. M., and Ryzhkov, A. V.: Correlation coefficients between horizontally and vertically polarized returns from ground clutter, J. Atmos. Ocean. Tech., 23, 381-394, 2006. 